\title{
Development of a Conceptual Framework for e-Health Readiness Assessment in the Context of Developing Countries
}

\author{
Kabelo Leonard MAUCO ${ }^{\mathrm{a}, \mathrm{b}, 1}$, Richard E SCOTT ${ }^{\mathrm{a}, \mathrm{c}}$ and Maurice MARS ${ }^{\mathrm{a}, \mathrm{d}}$ \\ ${ }^{a}$ Department of TeleHealth, University of KwaZulu-Natal, Durban, South Africa \\ ${ }^{\mathrm{b}}$ Botho University, Gaborone, Botswana \\ ${ }^{c}$ Department of Community Health Sciences, Cumming School of Medicine, University \\ of Calgary, Calgary, Alberta, Canada \\ ${ }^{d}$ College of Nursing and Health Sciences, Flinders University, Adelaide, South \\ Australia, Australia
}

\begin{abstract}
Background: e-Health readiness has been described as the preparedness of healthcare institutions, communities, or individuals for the anticipated change brought by programmes related to ICT use. Assessment of e-health readiness prior to the implementation of e-health innovations can therefore facilitate the process of change for individuals and organisations to adopt e-health programmes and avoid disappointment. The literature shows that although many e-health readiness assessment frameworks and tools exist, none meet all the requirements for e-health readiness assessment in developing countries. The aim of this study was to develop an e-health readiness assessment framework applicable to developing countries. Methods: A three-step process gleaned from the e-health literature (literature review / material collection; analysis / content analysis; consolidation / conceptual framework synthesis), together with iterative and reflective processes based on prior research undertaken by this group, guided framework conceptualisation and design. Results: An evidence-based framework was developed that: incorporates the need to assess readiness for each e-health component separately; identifies government's central role in engaging all relevant stakeholders; and the need to assess the adequacy of a country's infrastructure and infostructure prior to e-health planning and possible implementation. Also addressed by the framework is a need for an ehealth readiness assessment to be undertaken using separate tools for technical and non-technical individuals. A country's e-Readiness is highlighted as an important indicator for e-health readiness. Conclusions: The intent of the final framework is to inform and assist policy and decision makers, and facilitate future successful implementation of e-health initiatives in the developing world.
\end{abstract}

Keywords. e-Health, readiness assessment, frameworks, models, developing countries

\section{Introduction}

e-Health has been defined as the use of information and communication technologies (ICT) in support of health and health related fields, including healthcare services; health surveillance; health literature; health education, knowledge and research [1]. e-health has

1 Corresponding Author: Kabelo Leonard Mauco, Department of Telehealth, University of KwaZulu-Natal, South Africa and Botho University, Botswana; Email: kabelo.mauco@bothouniversity.ac.bw 
been an area of priority for the World Health Organization since 2005 and has been suggested to comprise of four elements: e-commerce (business), e-learning (training awareness, teaching, instruction, and education), health informatics (data gathering, storage, analysis, and distribution), and telehealth, including telemedicine (either interactive real-time or store and forward activity) [2].

Implementation of e-health innovations continues to grow and mature in both the developed and developing world [2-4]. Developing countries face health challenges that could be ameliorated by e-health implementation, including a shortage of healthcare resources [5] and challenges with healthcare quality, accessibility and affordability [6]. Despite benefits associated with e-health, implementation failures unrelated to the ehealth technology used have also been reported [2,7]. A majority of these failures might actually be related to a lack of e-health readiness.

e-Health readiness has been described as the preparedness of healthcare institutions, communities, or individuals for the anticipated change brought by programmes related to ICT use [8]. Assessment of e-health readiness prior to implementation of e-health innovations can therefore facilitate the process of change for individuals and organisations to adopt e-health programmes and avoid disappointment [9]. e-Health readiness assessment has been considered crucial to the successful adoption and sustainability of e-health implementations for the last two decades [10-12]. Indeed, the importance of readiness has been documented and described in various developing country settings and for various uses as both key to successful e-health implementation and as a factor in failed implementations [11-15]. It can be assumed that successful implementation of e-health cannot be achieved without the readiness of the broad spectrum of stakeholders and users (providers, patients, public, politicians, public servants, managers and industry). A recent study noted that even though many e-health readiness assessment frameworks (eHRAFs) exist in the literature, none was entirely suitable for assessing e-health readiness in the context of developing countries [7]. Limitations included: some of the frameworks assumed an adequate pre-existing ICT infrastructure, awareness of planned e-health interventions by respondents, the presence of available Internet connectivity, a healthcare sector with established e-health services, or the presence of sustained government will and support, and finally no framework assessed Internet awareness or all eight common readiness areas [7,8,16]. Given the ubiquity and importance of e-health for developing countries, a suitable eHRAF relevant to their needs is required.

This study is founded on a structured review of the literature on existing e-health readiness assessment frameworks and interviews with local in-country experts already conducted by this group. The structured review evaluated suitability of existing e-health readiness assessment frameworks for use in developing countries [7]. Eight e-health readiness assessment types were identified and defined, organisational readiness, technological-infrastructural readiness, government readiness, societal readiness, healthcare provider readiness, engagement readiness, core readiness and public-patient readiness (Table 1). The frameworks identified varied in underlying assumptions and perspectives, lacked any unifying theory, and often failed to address government readiness, societal readiness, and cultural readiness, and highlighted the need for separate assessment of each e-health component and user segment [7]. Interviews with purposively selected relevant experts in Botswana elucidated additional factors to be considered when assessing e-health readiness in the context of developing countries. Thematic analysis of the interviews identified four major e-health readiness themes: stakeholder issues, resources, access, and governance (national and institutional) [17]. 
Building upon prior research, this study designs and creates a conceptual framework for a developing country-specific e-health readiness assessment. A conceptual framework is a diagram that summarises a complex setting or system in a way that researchers believe can best illustrate key evidence-based factors and explain relationships between these factors. The goal is to facilitate an understanding of a complex setting in a simplified and accessible fashion.

The aim of this paper is to describe development of an eHRAF that will inform policy- and decision-makers and facilitate future successful implementation of e-health initiatives in the developing world.

Table 1. Definitions of e-Health readiness assessment types obtained from literature review [7].

\begin{tabular}{|c|c|}
\hline e-Health readiness assessment type & Definition \\
\hline Organizational readiness & $\begin{array}{l}\text { Gauges the extent to which the institutional setting and } \\
\text { culture supports and promotes awareness, implementation, } \\
\text { and use of e-health innovations (e.g., presence of relevant } \\
\text { policies; senior management support). }\end{array}$ \\
\hline $\begin{array}{l}\text { Technological/Infrastructural } \\
\text { readiness }\end{array}$ & $\begin{array}{l}\text { Gauges the availability and affordability of ICT resources } \\
\text { necessary to implement a proposed e-health innovation (e.g., } \\
\text { skilled human resources, ICT support, quality ICT } \\
\text { infrastructure, and power supply. }\end{array}$ \\
\hline Healthcare provider readiness & $\begin{array}{l}\text { Gauges the influence of a healthcare provider's personal } \\
\text { experience; primarily their perception and receptiveness } \\
\text { towards the use of e-health technology. }\end{array}$ \\
\hline Engagement readiness & $\begin{array}{l}\text { Gauges the extent to which members of a community are } \\
\text { exposed to the concept of e-health and are actively debating } \\
\text { its perceived benefits as well as negative impacts. It also } \\
\text { involves gauging the willingness of members of a community } \\
\text { to accept training on e-health. }\end{array}$ \\
\hline Societal readiness & $\begin{array}{l}\text { Gauges the degree of 'interaction' associated with a } \\
\text { healthcare institution. Interaction is described by three } \\
\text { parameters; interaction among members of a healthcare } \\
\text { institution, interaction of a healthcare institution with other } \\
\text { healthcare institutions, and interaction of a healthcare } \\
\text { institution with its local communities. }\end{array}$ \\
\hline Core readiness & $\begin{array}{l}\text { Gauges the extent to which members of a community are } \\
\text { dissatisfied with the current status of their healthcare service } \\
\text { provision, see e-health as a solution, and express their need } \\
\text { and preparedness for e-health services. }\end{array}$ \\
\hline Government readiness & $\begin{array}{l}\text { Gauges the extent to which a country's Government and } \\
\text { politicians support and promote awareness, implementation, } \\
\text { and use of e-health innovations (e.g., presence of relevant } \\
\text { policies, and funding). }\end{array}$ \\
\hline Public/Patient readiness & $\begin{array}{l}\text { Gauges the extent to which members of the public and } \\
\text { patients are aware of, and can afford and access, e-health } \\
\text { services. It also involves gauging the influence of their } \\
\text { personal experiences on their perception and receptiveness } \\
\text { towards the use of e-health technology. }\end{array}$ \\
\hline
\end{tabular}

\section{Methods}

Although 'conceptual frameworks' can readily be found in the literature, there is very little specific guidance for a process by which to design and develop a conceptual framework for application to e-health. Some fundamental steps were identified from the literature. These were: 'literature review, analysis, and consolidation' [18], or 'material 
collection, content analysis, and conceptual framework synthesis' [19]. In the absence of a standardised method for conceptual framework development, a similar three step approach was used, namely: 'literature review / material collection', 'analysis / content analysis', and 'consolidation / conceptual framework synthesis'.

To ensure development of an evidence-based conceptual framework, the findings from two prior studies (a literature review [7], and consultation process with e-health experts in Botswana [17]) were used as the evidence-base. Together, these studies satisfied the first two steps of the approach: literature review / material collection, followed by analysis / content analysis.

Thereafter a 'consolidation / conceptual framework synthesis' step was undertaken. The initial consolidation process involved the authors identifying all key elements relevant to and essential for inclusion in an eHRAF for developing countries. Identification of these key elements was guided by prior work which had 1) provided agreed definitions of terms relating to e-health readiness, and 2) grouped various aspects or facets that impact e-health readiness into distinct dimensions [7, 17]. Using an inductive iterative approach, this collective knowledge was conceptualised and processed into preliminary designs to build a framework that illustrated relationships between the identified key elements and their role in determining e-health readiness.

The inductive, iterative and reflective processes guiding framework design ceased when the underlying principles of the framework appeared plausible, and the framework was considered sufficiently robust that it could be used to guide e-health implementation through understanding how to effect change and bring about improved e-health readiness. Thereafter, the proposed framework was assessed by the authors to determine if it 'fitted' the desired purpose. This assessment involved the authors reflecting on their previous work, as well as their experience of past settings as cases, and gauging if the framework was practical and understandable, and revising it by removing or adding any element considered redundant or missing.

\section{Results}

The proposed e-health readiness assessment framework (eHRAF) for developing countries is presented in Figure 1. The framework first illustrates the overarching role of e-readiness of a setting which will inevitably impact e-health readiness. The framework then highlights separate and distinct assessment of e-health readiness for each component of e-health (health informatics, telehealth, e-commerce, and technology enabled learning), and the need for separate e-health readiness assessment tools for each component and for technical and non-technical individuals (e.g., ICT staff versus clinicians and managers). Two aspects are then identified as essential factors in determining an e-health ready setting, both of which require specific assessment at different points in time. First, the presence of stakeholder engagement, ideally addressed early in the process, i.e., from inception. 
e-Health

[ Components: Health Informatics; Telehealth; e-Commerce; Technology Enabled Learning ] e-Health Readiness l e-Health Readiness Assessment

[For Each e-Health Component: Specific Tools for Technical and Non-technical Individuals ]

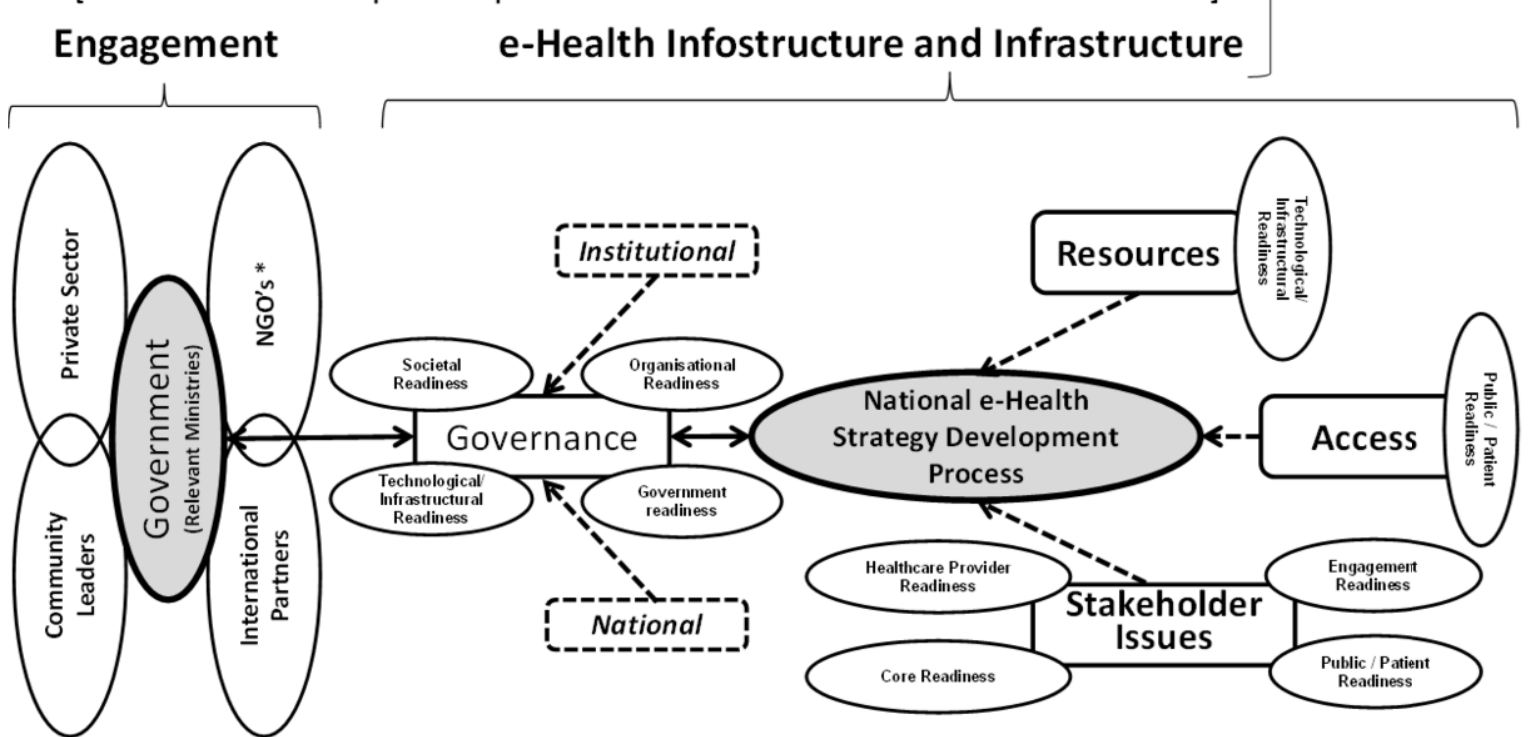

${ }^{*}$ Includes Humanitarian and Faith-Based Organisations

Figure 1. e-Health readiness assessment framework (eHRAF) for developing countries. 
Second, the presence of relevant e-health infostructure and infrastructure, ideally addressed later in the process once specific e-health solutions have been identified.

Within the framework, government is at the core of stakeholder engagement (Figure 1). Illustrated categories of relevant and essential stakeholders to be engaged are: the private sector, community leaders, international partners, as well as nongovernmental organisations (NGOs), humanitarian organisations, and faith-based groups. The need for development of a comprehensive and informed national e-health strategy as a prerequisite to e-health readiness is shown.

\section{Discussion}

While developed specifically for application in the context of developing countries, the proposed conceptual framework also attempts to unify those existing e-health readiness assessment frameworks gathered from a prior literature review. The framework presented in this paper provides insight regarding how multiple factors interact to influence the e-health readiness of a given setting, and how this knowledge helps identify specific actions and interventions that help lead to successful e-health implementation, in the developing country context. Each country will need to fine tune the framework when applying it, based on local circumstances.

Shuvo et al. identified a number of important issues relevant to implementation, as well as scale-up and sustainability, for e-health initiatives in low- and middle-income countries [20]. These issues, although termed slightly differently, were also identified within the framework presented here. However, the framework presented here is more comprehensive (addressing all eight common readiness areas, [7]), and deals with an expanded content at a higher level and in a more programmatic fashion.

Emphasised in the current framework is the use of stakeholder specific assessment tools to avoid challenges, like those experienced in a previous study in a different developing world setting where a generic e-health readiness assessment tool was used. Study participants failed to respond to some questions because they were unfamiliar with specific matters raised, or because they felt they did not have the (political) authority to answer the questions [16]. This illustrates that the use of a single generic tool for e-health readiness assessment within any framework has the potential to negatively affect the validity of such an assessment. Indeed, the same sentiment was expressed by Khoja et al. who in their study developed separate e-health readiness assessment tools for managers and healthcare providers, so that e-health readiness could be determined from both perspectives [8].

e-Health consists of various components including health informatics, telehealth, ecommerce, as well as technology enabled learning [2]. As previously discussed, to assess e-health readiness comprehensively the various components must all be taken into consideration [7]. Furthermore, readiness for one component does not necessarily translate to an overall e-health readiness, or readiness for any other specific component.

e-Readiness, of which e-health readiness is just one aspect, has been defined as a measure of the quality of a country's ICT infrastructure and the ability of its consumers, businesses and governments to use ICT to their benefit [21]. When assessing e-readiness for Estonia, the PRAXIS Centre for Policy Studies used the following indicators: network access, networked society, networked education, and networked economy [22]. As such, the degree of e-readiness of a country has a direct influence on its e-health readiness. 
In developing countries e-health is largely funded, directly or indirectly, by external donors and government, as opposed to private enterprise, which is somewhat different to many developed countries. Thus, foreign NGOs, faith-based groups, and multinational institutions have been involved in the funding of e-health projects in many developing countries, including India, Uganda, Rwanda, Zambia, Ethiopia and Tanzania [23, 24]. The role of the private sector in the development of better health systems and the improvement of healthcare has also been documented, creating a need for the private sector to be more engaged in the process of focussed and 'evidence-based health need' e-health implementation [2]. Medical aid providers, mobile network operators, the TelCom industry in general, technology developers, the financial industry, as well as private healthcare providers, are some of the private sector candidates whose engagement can result in provision of e-health friendly solutions, thus contributing to e-health readiness.

The framework also illustrates the central role that government needs to play in ensuring e-health readiness [25]. This involves engaging all relevant stakeholders, including potential funders. Barkman and Weinehall [26] have emphasised the need for such a central role to be played by the government, noting that political responsibility lies in creating optimal conditions for m-health implementation, in terms of both infrastructure and regulatory framework. Beebeejaun and Chittoo [27] have documented the important role of government policies in maximizing the probability of success in implementing information systems. Similarly, Bloom et al. emphasised the importance of government to protect the interests of the 'poor and politically weak' and to 'engage actively in the innovation process' as a new health knowledge economy was shaped [28]. A study by Abel and Obeten [23], concluded that lack of political will was one of the reasons why foreign NGOs and multinational institutions were not as eager to fund ehealth projects in Nigeria as they did in other developing countries. A report on assessment of e-health projects and initiatives in Africa noted that e-health projects funded by external donor agencies ceased when the donor funding was exhausted [29]. As such in ensuring sustainable implementation of e-health projects and hence e-health readiness, a government need not depend on external funding alone for its e-health projects but also on itself. Insufficient government funding in adopting e-health solutions has been documented as one of the contributing factors to failed implementations [30].

The importance of stakeholder engagement when implementing e-health initiatives has been appreciated for some time [31-33]. It is generally considered a change management issue and to entail communication approaches to provide rational business reasons and to manage the less rational emotional reactions to the change [34]. Of primary importance, although seldom achieved, is the engagement of all relevant stakeholders at the outset of e-health implementation, which results in coordinated efforts and promotes awareness and e-health readiness through stakeholder buy-in.

In most communities in developing countries, especially in Africa, there exists a social structure headed by community leaders who could be chiefs or councillors. Involvement of such community leaders during the engagement process ensures that any public concerns and expectations with regards to e-health are considered hence promoting engagement readiness, public/patient readiness, core readiness and - to some extent - healthcare provider readiness and societal readiness [7].

The framework also illustrates that the efforts from such engagements need to inform the process of national e-health strategy development. A national e-health strategy, and its development process, is core to e-health readiness as it provides guidance for implementation. This guidance includes recognition of relevant 
infrastructure as well as providing a conducive e-health infostructure. Infostructure, a term used in many disciplines [35] is inconsistently defined, and must be differentiated from the accepted term infrastructure (e.g., transportation, power supplies). Adapting the work of Latif et al. [35] in the realm of e-health, infostructure can be considered the soft elements that support infrastructure, and includes elements of human resources, organisational and administrative structures, policies, regulations and incentives.

The importance of a national e-health strategy in strengthening e-health implementation is also emphasised in the national e-health strategy toolkit of the World Health Organization (WHO) and International Telecommunication Union as well as by other authors [33, 36, 37]. Indeed, strategy has been stated to be the driving force that places countries in charge of their own e-health destiny [34]. Thematic analysis of expert interviews (Table 2) highlighted the four themes of governance, resources, access, and stakeholder issues as areas necessary to be considered during development of a national e-health strategy and towards achieving e-health readiness.

The framework's primary strength is that it has been intentionally designed to address the needs of developing countries. It is also more comprehensive than other published frameworks which only directly address, at most, four of the eight readiness areas identified in prior research [7]. In addition, the study is evidence-based being formulated from the literature and expert opinion. A potential weakness is the restriction of experts to one country, since experts from differing countries may have differing opinions about the relevance or emphasis of constructs. The effectiveness and value of the current framework must be empirically demonstrated.

Table 2. e-Health readiness themes and subthemes from expert interviews [17]

\begin{tabular}{|c|c|c|c|}
\hline Governance & Stakeholder issues & Resources & Access \\
\hline $\begin{array}{ll}\text { National Governance } \\
\text { - } & \text { Political will } \\
\text { - } & \text { Legal framework } \\
& \text { } \text { plan } \\
\text { - } & \text { Public private } \\
\text { - } & \text { partnerships } \\
\text { e-Governance } & \text { - e-health leverage } \\
\text { - } & \text { Healthcare service } \\
& \text { delivery } \\
\text { - unique patient } \\
\text { identifier } \\
\text { - population } \\
\text { distribution } \\
\text { - health facility } \\
\text { distribution } \\
\text { Power supply } \\
\text { Institutional Governance } \\
\text { - } \quad \text { Policies } \\
\text { - } \quad \text { Integulations } \\
\text { - } \quad \text { Data stewardship } \\
\text { resources } \\
\end{array}$ & $\begin{array}{ll}\text { - } & \text { Engagement } \\
\text { - } & \text { Public awareness } \\
\text { - } & \text { Readiness } \\
\text { - } & \text { Change } \\
& \text { management }\end{array}$ & $\begin{array}{ll}\text { - } & \text { Budget } \\
\text { - } & \text { ICT infrastructure } \\
\text { ICT infostructure } \\
\text { - electronic health } \\
\text { records } \\
\text { - } \text { Human resources } \\
\text { - human health } \\
\text { resources } \\
\text { - human e-health } \\
\text { resources }\end{array}$ & $\begin{array}{ll}\text { - } & \text { Literacy } \\
\text { - technical literacy } \\
\text { - } & \text { Training } \\
\text { - curriculum } \\
\text { - } & \text { Network reach } \\
\text { - } & \text { Internet } \\
\text { availability } \\
\text { - } \\
\text { Affordability of } \\
\text { access to e-media } \\
\text { - Ubiquity to access } \\
\text { e-services } \\
\text { - Access to e- } \\
\text { devices } \\
\text { - Presence to access } \\
\text { electronic health } \\
\text { records } \\
\text { Availability of e- } \\
\text { health resources in } \\
\text { local languages } \\
\text { Rate of social } \\
\text { media usage } \\
\text { e-health support }\end{array}$ \\
\hline
\end{tabular}




\section{Conclusion}

The e-health readiness assessment framework (eHRAF) presented is evidence-based, being developed using inputs gained from prior developing country research. This includes a structured review of the literature, a critical analysis of existing eHRAFs, and expert opinion regarding essential readiness themes. These inputs were then used to create and assess a new framework that identifies essential dimensions of readiness and how their relationships and points of intersection can be used to influence readinessrelated activities and interventions. The output is a framework whose understanding, and use will inform policy- and decision-makers, and facilitate future successful implementation of e-health initiatives in the developing world.

\section{Acknowledgements}

Research reported in this publication was supported by the Fogarty International Center of the National Institutes of Health under Award Number D43TW007004-13. The content is solely the responsibility of the authors and does not necessarily represent the official views of the National Institutes of Health.

\section{References}

[1] Gholamhosseini L, Ayatollahi H. The design and application of an e-health readiness assessment tool, Health Inf Manag 2017 46: 32-41.

[2] Scott R, Mars M. Telehealth in the developing world: current status and future prospects, Smart Homecare Technol Telehealth 3. 2015. p. 25-37.

[3] World Health Organization, From innovation to implementation-eHealth in the WHO European region, Copenhagen, Denmark. 2016.

[4] Kiberu VM, Mars M, Scott RE. Barriers and opportunities to implementation of sustainable e-Health programmes in Uganda: a literature review, Afr J Prim Health Care Fam Med 9. 2017. p. 1-10.

[5] Bangdiwala SI, Fonn S, Okoye O, Tollman S. Workforce resources for health in developing countries, Public Health Rev 32. 2010 p. 296-318.

[6] Rahman A. Current status and potential of e-health in developing countries: a review, Dhaka: BRAC University. 2016.

[7] Mauco KL, Scott RE, Mars M. Critical analysis of e-health readiness assessment frameworks: suitability for application in developing countries, J Telemed Telecare 24. 2018. p. 110-117.

[8] Khoja S, Scott R, Casebeer A. e-Health readiness assessment tools for healthcare institutions in developing countries, Telemed J E Health 13 (2007), 425-431.

[9] Khoja S, Scott R, Gilani S. E-health readiness assessment: promoting "hope" in the health-care institutions of Pakistan, World Hosp Health Serv 44. 2008. p. 36-38.

[10] Jennett PA, Andruchuk K. Telehealth: 'real life' implementation issues, Comput Meth Prog Bio 642001. p. 169-174.

[11] Qureshi QA, Qureshi NA, Chishti KA, et al. E-readiness: a critical factor for successful implementation of eHealth projects in developing countries like Pakistan, Gomal Univ J Res 30. 2014 p. 77-86.

[12] Scott RE, Mars M. e-Health: 'Ready' - 'Set' - 'Go': Are We Still Stuck on 'Ready'?, in: Global telemedicine and ehealth updates: knowledge resources, International Society for Telemedicine and eHealth 8. 2015. p. 158-162.

[13] Biruk S, Yilma T, Andualem M, et al. Health professionals' readiness to implement electronic medical record system at three hospitals in Ethiopia: a cross sectional study, BMC Med Inform Decis Mak 2014 $14(1) ; 115$.

[14] Habibi-Koolaee M, Safdari R, Bouraghi H. Nurses readiness and electronic health records, Acta Inform Med. 2015 23(2):105.

[15] Saleh S, Khodor R, Alameddine M, et al. Readiness of healthcare providers for eHealth: the case from primary healthcare centers in Lebanon, BMC Health Serv Res. 2016 16(1):644. 
[16] Chipps J, Mars M. Readiness of healthcare institutions in KwaZulu-Natal to implement telepsychiatry, J Telemed Telecare 18. 2012 p. 133-137.

[17] Mauco KL, Scott RE, Mars M, Development of an ehealth readiness assessment framework for Botswana and other developing countries: interview study, JMIR Med Inform. 2019 7(3), e12949.

[18] Khoja S, Durrani H, Scott RE, Sajwani A, et al. Conceptual framework for development of comprehensive e-health evaluation tool, Telemed J E Health. 2013 19(1) 48-53.

[19] Sarantis D, Soares DS. From a literature review to a conceptual framework for health sector websites' assessment, in: Electronic Government: 16th IFIP WG 8.5 International Conference, EGOV 2017, Springer International. 2017 p. 128-141.

[20] Shuvo TA, Islam R, Hossain S, et al. e-Health innovations in LMICs of Africa and Asia: a literature review exploring factors affecting implementation, scale up, and sustainability, Innov Entrep Health 2 2015 p. 95-106.

[21] Economist Intelligence Unit - IBM Institute for Business Value, E-readiness rankings 2009: The usage imperative, The Economist Intelligence Unit Limited, 2009.

[22] Krull A. ICT infrastructure and e-readiness assessment report: Estonia, Tallinn: PRAXIS Center for Policy Studies, 2003.

[23] Abel EE, Obeten E. Funding e-health in Nigeria by NGOS/multinational organization: Overview and perspectives, Int J Comput Appl 2015, 111(11), 37-41.

[24] United Republic of Tanzania Ministry of Health and Social Welfare, Tanzania national e-health strategy 2012-2018, draft, Dar es Salaam: United Republic of Tanzania Ministry of Health and Social Welfare, 2013.

[25] Ngoc CT, Bigirimana N, Muneene D, Bataringaya JE, et al. Conclusions of the digital health hub of the Transform Africa Summit: strong government leadership and public-private-partnerships are key prerequisites for sustainable scale up of digital health in Africa, BMC Proc 12. 2018 (1) 17.

[26] Barkman C, Weinehall L. Policymakers and mHealth: roles and expectations, with observations from Ethiopia, Ghana and Sweden, Glob Health Action 10. 2017; 1337356.

[27] Beebeejaun MR, Chittoo H. An assessment of e-health readiness in the public health sector of Mauritius, Int J Sci Basic Appl Res. 2017 35(1), 193-210.

[28] Bloom G, Berdou E, Standing H, et al, ICTs and the challenge of health system transition in low and middle-income countries, Glob Health 13. 2017; 56.

[29] Molefi M. An assessment of ehealth projects and initiatives in Africa, World Health Organization, (2010).

[30] Ranasinghe KI, Chan T, Yaralagadda P. Information support for health management in regional Sri Lanka: health managers' perspectives, Health Inf Managt. 2012 41(3), $20-26$.

[31] Ministerial summit on health research, World Health Assembly 58th Meeting Agenda item. 2005 p. 25.

[32] Kwankam SY. Successful partnerships for international collaboration in e-health: the need for organized national infrastructures, Bull World Health Org 90. 2012, 395-397.

[33] World Health Organization and International Telecommunication Union, National eHealth strategy toolkit overview (2012). Available from: https://www.who.int/ehealth/publications/overview.pdf

[34] Carr D, Howells A, Chang M, Hirji N, et al. An integrated approach to stakeholder engagement, Healthc Q. 200912 p. 62-70.

[35] Latif AA, Arshad NH, Janom N, Use of infostructure for disaster: towards definition of infostructure, Proceedings of the $5^{\text {th }}$ International Conference on Computing and Informatics (ICOCI 2015). 2015, pp. 728-36.

[36] Jones T. Developing an e-health strategy: a commonwealth workbook of methodologies, content and models, Commonwealth Secretariat. 2011.

[37] Scott R, Mars M. Principles and framework for e-health strategy development, JMIR 2013, 15(7), e155. 